\title{
Relationship of serum C-reactive protein and uric acid concentration with proportion of albuminuria in patients with type 2 diabetes mellitus
}

\author{
Foroogh Sabzghabaei $^{(\mathbb{D}}$, Hajar Rajabian \\ Department of Medicine, Firoozgar Hospital, Iran University of Medical Sciences, Tehran, Iran
}

\section{A R T I C L E I N F O}

\section{Article Type:}

Original

\section{Article History:}

Received: 3 November 2017

Accepted: 19 December 2017

Published online: 15 January 2018

\section{Keywords:}

Albuminuria

Type 2 diabetes mellitus

Uric acid

\begin{abstract}
A B S T R A C T
Introduction: Prevalence of diabetes and its complications will be considerably increased in the future. This study focused on the correlation of some laboratory parameters with prevalence and severity of diabetic nephropathy which is the main cause of chronic renal failure (CRF) in our country.

Objectives: Regarding the importance of diabetic nephropathy and lack of studies on the effect of serum C-reactive protein (CRP) and uric acid on albuminuria and its severity, the current study was designed.

Methods: Through an analytic cross-sectional design, 200 type 2 diabetes mellitus (T2DM) cases were recruited between 2014 and 2015. Blood samples were drawn after 12 hours of starving to measure parameters including serum levels of CRP, triglyceride (TG) and highdensity lipoprotein cholesterol (HDL-C), cholesterol, Low-density lipoprotein (LDL-C), fasting blood sugar (FBS), and Hb-A1C. Albuminuria was assessed by collecting participants' 24 hours urine.

Results: Macro-albuminuria correlated with high serum uric acid (SUA) (odds ratio $[\mathrm{OR}]=1.3)$ and high serum CRP $(\mathrm{OR}=1.2)$ among diabetic patients. Both markers represented significant correlation with albuminuria. Logistic regression test confirmed the mentioned correlation when confounding factors were eliminated.

Conclusion: It seems that uric acid and CRP levels in serum are the most reliable parameters studied by the current study to predict life-threatening diabetic consequences like cardiovascular and chronic kidney disease in patients with type II diabetes mellitus.
\end{abstract}

Implication for health policy/practice/research/medical education:

Prevalence of diabetes and its complications will be considerably increased in the future. This study focused on the correlation of some laboratory parameters with prevalence and severity of diabetic nephropathy which is the main cause of chronic renal failure in our country.

Please cite this paper as: Sabzghabaei F, Rajabian H. Relationship of serum C-reactive protein and uric acid concentration with proportion of albuminuria in patients with type 2 diabetes mellitus. J Renal Inj Prev. 2018;7(4):246-252. doi: 10.15171/jrip.2018.56.

\section{Introduction}

Diabetic nephropathy is the most common cause of chronic renal failure (CRF) in the Western world (1) and in charge for $45 \%$ of renal transplantation cases while being one of the main causes of cardiovascular diseases (2). A pronounced increase in cases of diabetic nephropathy shows epidemic rise of obesity, metabolic syndrome and type 2 diabetes mellitus (T2DM) in recent decades. Hence, recognition of relevant risk factors and early diagnosis is vital in manage and follow up the subjects (3).
Hyperglycemia, hypertension and dyslipidemia are the most known pathophysiologic factors of diabetic nephropathy which all have inflammatory basis (4). Numerous studies revealed that subclinical chronic inflammation is also associated with insulin resistance syndrome to play a predominant role in the pathogenesis of diabetic nephropathy (5). C-reactive protein (CRP), made and released by liver macrophages as well as adipocytes, is an acute phase protein as a sensitive marker of inflammation in the early phase (6). It is possible that 
serum CRP correlates with diabetic nephropathy and neuropathy in type 1 and 2 of DM (7). Furthermore, uric acid as the final metabolite of purines, is an independent risk factor of renal dysfunction among patients with DM (8). Pieces of evidence showed that serum levels of uric acid could directly induct increased cytokines in blood flow like CRP, INF and IL-6 to cause renal dysfunction and augmentation of albumin excretion in urine (9). This means that high serum levels of uric acid may be a predictor for hypertension (10), Obesity (11), T2DM (12), metabolic syndrome (13) and cardiovascular diseases as well as reduced glomerular filtration rate (GFR) (14). CRP is usually released after uric acid enters vascular smooth muscles to activate an inflammatory cycle and endothelial dysfunction which, in turn, increases the risk of albuminuria in DM cases (15). Bonakdara et al evaluated 1275 cases of T2DM in 2011 to determine that high serum level of uric acid correlated with high albuminuria in that group of patients (16). Yan et al assessed separate effects of serum CRP and uric acid on albuminuria in DM patients (17). In addition, some authors believe that Tumor necrosis factor alpha (TNF- $\alpha$ ) is also an inflammatory marker which its higher serum levels in addition to increased serum CRP is associated with higher risk of albuminuria (18).

\section{Objectives}

Regarding the importance of diabetic nephropathy and lack of studies on their effect of serum CRP and uric acid on albuminuria and its severity in our country, the current study intended to assess this effect among patients with $\mathrm{T} 2 \mathrm{DM}$ in order to prevent it or achieve a good way to manage.

\section{Patients and Methods \\ Study population}

Through an analytic cross-sectional design, 200 T2DM cases were recruited by the current study. They referred to Firoozgar hospital in Tehran between 2014 and 2015. Patients with other types of diabetes, kidney disease or transplantation, subjects with kidney vascular problems and dialysis in addition to people who had obstructive uropathy, urinary tract infections, fever, acute medical conditions, congestive heart failure and malignancies as well as pregnant patients were excluded. Taking uric acid lowering medications were also considered as exclusion criteria as well. Demographics, vital signs and other clinical findings were gathered by a questionnaire. Blood samples were drawn after 12 hours of starving to measure parameters including serum levels of CRP, triglyceride (TG) and high-density lipoprotein cholesterol (HDL-C), cholesterol, Low-density lipoprotein (LDL-C), fasting blood sugar (FBS), and Hb-A1C. Among which, for the first parameter we used an immunoturbidimetric method and the rest were assessed through enzymatic methods. Twenty-hour urine albumin level was measured with immunoturbidimetric method too. Past medical history, current treatments, duration of illness and smoking history were obtained as well.

\section{Ethical issues}

1) The research followed the tenets of the Declaration of Helsinki; 2) informed consent was obtained and 3) the research was approved by the ethical committee of Iran University of Medical Sciences (\#94-01-30-25796).

\section{Data analysis}

Regarding the Cochrane's sample size formulation and considering study power of 0.8 , CI of 95\%, a type 1 error of 0.05 and the following formula the sample size was calculated $(\mathrm{N}=200)$.

$$
n=\frac{(N \times t 2 \times p \times q)}{(N \times d 2+t 2 \times p \times q} ; d=0.2, t=1.6
$$

Data entered statistical software to analyze with chi-square and $t$ test in addition to logistic regression and analysis of variance (ANOVA). Quantitative data were reported using central tendencies and qualitative were claimed by percentages. Chart spots were provided using logistic regressions.

\section{Results}

A total of 200 patients with T2DM enrolled the current study including 108 (54\%) males and 92(46\%) females between 38 and 78 years of age. The mean age was $54.42 \pm 9.28$ years. The majority of the participants were in their 50's (38\%) followed by patients younger than 50 years of age $(36.5 \%)$ and older than $60(25.5 \%)$. The least body mass index (BMI) was $19.52 \mathrm{~kg} / \mathrm{m}^{2}$ and its most value was $37.06 \mathrm{~kg} / \mathrm{m}^{2}$ with the mean of $26.58 \pm 3.52 \mathrm{~kg} /$ $\mathrm{m}^{2}$. On average, the total time of involvement with T2DM was $8.15 \pm 5.62$ years. Our patients had the disease from 1 to 30 years and $80.5 \%$ of them had the disease for less than 10 years. Of the participants, 46 (23\%) were cigarette smokers. Table 1 summarizes the mentioned demographics and background information. The most used medical regimen to control DM was a combination of insulin and oral medications in 99 (49.5\%) of patients while oral medications were administered alone in $35.5 \%$. Insulin was the only medication in $15 \%$ of the cases. Systolic blood pressure ranged $80-190 \mathrm{~mm} \mathrm{Hg}$ and diastolic pressure $40-110 \mathrm{~mm} \mathrm{Hg}$. The means of systolic and diastolic blood pressures were $125.2 \pm 16.63 \mathrm{~mm} \mathrm{Hg}$ and $76.82 \pm 8.58 \mathrm{~mm} \mathrm{Hg}$, respectively. Table 2 shows the laboratory parameters of patients.

Serum uric acid (SUA) ranged 2.1-9.1 $\mathrm{mg} / \mathrm{dL}$ with a mean of $5.11 \pm 1.42 \mathrm{mg} / \mathrm{dL}$ while CRP had a mean of $2.72 \pm 2.81$ $\mathrm{mg} / \mathrm{L}$ and ranged $0.03-15.3 \mathrm{mg} / \mathrm{L}$. Total 24 hours urine albumin ranged $1.3-485 \mathrm{mg} / \mathrm{d}$ with $66.35 \pm 99.07 \mathrm{mg} / \mathrm{d}$ as mean \pm SD. More than a half of participants had albumin $<30 \mathrm{mg} / \mathrm{d}$ (albuminuria) in 24-hour urine while 79 (39.5\%) had micro-albuminuria (30-300 mg/d) and 8 (4\%) presented macro-albuminuria ( $>300 \mathrm{mg} / \mathrm{d})$ as can be seen in Table 1. Table 3 represents that SUA and serum CRP level were directly correlated with the total level of albumin in 24 hours urine $(P=0.007)$. Linear regression 
Table 1. Demographics and basic information of participants

\begin{tabular}{|c|c|c|}
\hline Variable & & No. (\%) \\
\hline \multirow{2}{*}{ Sex } & Male & $108(54)$ \\
\hline & Female & $92(46)$ \\
\hline \multirow{4}{*}{ Age $(y)$} & $<50$ & $73(36.5)$ \\
\hline & $51-60$ & $76(38)$ \\
\hline & $>60$ & $51(25.5)$ \\
\hline & Mean \pm SD & $54.42 \pm 9.28$ \\
\hline \multirow{4}{*}{ Duration of T2DM (y) } & $<10$ & $161(80.5)$ \\
\hline & $10-20$ & $29(14.5)$ \\
\hline & $>20$ & $10(5)$ \\
\hline & Mean \pm SD & $8.15 \pm 5.62$ \\
\hline \multirow{2}{*}{ Smoking habit } & No & $154(77)$ \\
\hline & Yes & $46(23)$ \\
\hline \multirow{5}{*}{ BMI $\left(\mathrm{kg} / \mathrm{m}^{2}\right)$} & $<9$ & $0(0)$ \\
\hline & $19-25$ & $74(37)$ \\
\hline & $25-30$ & $92(46)$ \\
\hline & $>30$ & $34(17)$ \\
\hline & Mean \pm SD & $26.5 \pm 3.52$ \\
\hline \multirow{4}{*}{ DM medications } & Oral & $71(35.5)$ \\
\hline & Insulin & $30(15)$ \\
\hline & Oral/Insulin combination & $99(49.5)$ \\
\hline & Total & $200(100)$ \\
\hline \multirow{3}{*}{ Albuminuria (mg) } & $<30$ & $113(56.5)$ \\
\hline & $30-300$ & 79 (39.5) \\
\hline & $>300$ & $8(4)$ \\
\hline
\end{tabular}

Table 2. Overall measurements of selected lab data to study with their maximum and minimum in participants

\begin{tabular}{llll}
\hline Parameter & (Mean \pm SD ) & Min & Max \\
\hline FBS (mg/dL) & $139.84 \pm 38.4$ & 75 & 280 \\
HBA $_{1}$ C (\%) & $7.41 \pm 1.41$ & 4 & 14.7 \\
TG (mmol/L) & $153.39 \pm 62.88$ & 36 & 470 \\
Cholesterol (mmol/L) & $168.73 \pm 64.04$ & 87 & 320 \\
LDL (mmol/L) & $98.44 \pm 34.89$ & 43 & 247 \\
HDL (mmol/L) & $39.9 \pm 10.6$ & 21 & 81 \\
Uric acid (mg/dL) & $5.11 \pm 1.42$ & 2.1 & 9.1 \\
CRP (mg/L) & $2.72 \pm 2.81$ & 0.03 & 15.3 \\
24-urine albumin(mg) & $66.35 \pm 99.07$ & 1.3 & 485 \\
\hline
\end{tabular}

test showed a diagram in this regard which is shown in Figure 1 . The correlation was statistically more observable between SUA level and 24-hour urine albumin and the related diagram shows it in a good way $(P<0.001)$.

Spearman's test also showed a significant direct correlation between serum CRP and SUA $(P=0.005)$, which its regression diagram is observable in Figure 1. Using $t$ test, the findings show no statistical relationship between age and $\mathrm{BMI}$ with the level of albuminuria $(P=0.78$ and $\mathrm{P}=0.49$ respectively). There was also no correlation between the chronicity of DM and albuminuria when compared by Mann-Whitney $U$ test $(P=0.321)$. The same results were obtained for systolic and diastolic blood pressure in terms of correlation with albuminuria and its severity $(P=0.102$ and $P=0.76$ respectively). Table 4 shows the related information perfectly. Gender, cigarette smoking
Table 3. Significance and coefficients of the direct correlation between SUA and CRP and the albumin concentration of 24-hour accumulated urine

\begin{tabular}{llll}
\hline & Parameter & Pearson's correlation & $\boldsymbol{P}$ value \\
\hline Albumin in & Serum uric acid & 0.242 & 0.001 \\
24-h urine & Serum CRP & 0.199 & 0.005 \\
\hline
\end{tabular}

and medications were the next parameters to be assessed if had any correlation with albuminuria. Chi-square test presented no correlation in this matter $(P=0.36, P=0.3$ and $P=0.15$ respectively). Kruskal-Wallis test was used to find any relationship among lipid profile, FBS and HBA1C with albuminuria but failed to find it in all groups and the findings are seen in Table 5. Interestingly, there was a correlation between serum TG level and albuminuria in three groups which we studied as reported by Table 5 $(P=0.025)$. SUA and serum CRP were compared in three levels of albuminuria using Kruskal-Wallis test to report strong correlations ( $P=0.0001$ for both).

As showed in Figure 2, macro-albuminuria closely correlated with high SUA and high serum CRP among diabetic patients. Both markers represented significant correlation with albuminuria level $(P=0.006$ and $P=0.003$ respectively). Logistic regression test confirmed the mentioned correlation when confounding factors were eliminated.

Additionally we found every unit of increased SUA could raise the risk of albuminuria up to 1.3 times which was feed by the odds ratio (OR) of 1.3 in the mentioned relationship while the OR for the role of CRP in the risk of albuminuria was 1.2 .

\section{Discussion}

The current study tried to disclose any correlation between two key laboratory parameters in a group of patients with DM who had no other comorbidities with effects on SUA and CRP levels. There were wide ranges of SUA and CRP among our patients and there were odds ratios 1.3 and 1.2 for uric acid and CRP, respectively in terms of correlation with the risk of albuminuria in diabetic cases that was near to the findings by Fraser et al, in 2014 (19). SUA and CRP were also in a direct strong relationship when studied in our participants.

Diabetic patients are basically at risk of many consequences from organ failures to disabilities and even early death. Uric acid, as an end product of purine metabolism in human, may lead to a wide spectrum of medical conditions which the most familiar one is gouty arthritis (20). Hyperuricemia has been also recently focused as a risk factor of cardiovascular diseases as well as metabolic syndrome (21). Furthermore, some count on hyperuricemia and metabolic syndrome as independent predictors of chronic kidney disease (CKD) in T2DM (22).

The current study did not compare SUA levels in different control levels of T2DM like HbA1C. Hence, we could not find any changes in uric acid to link to the levels of 

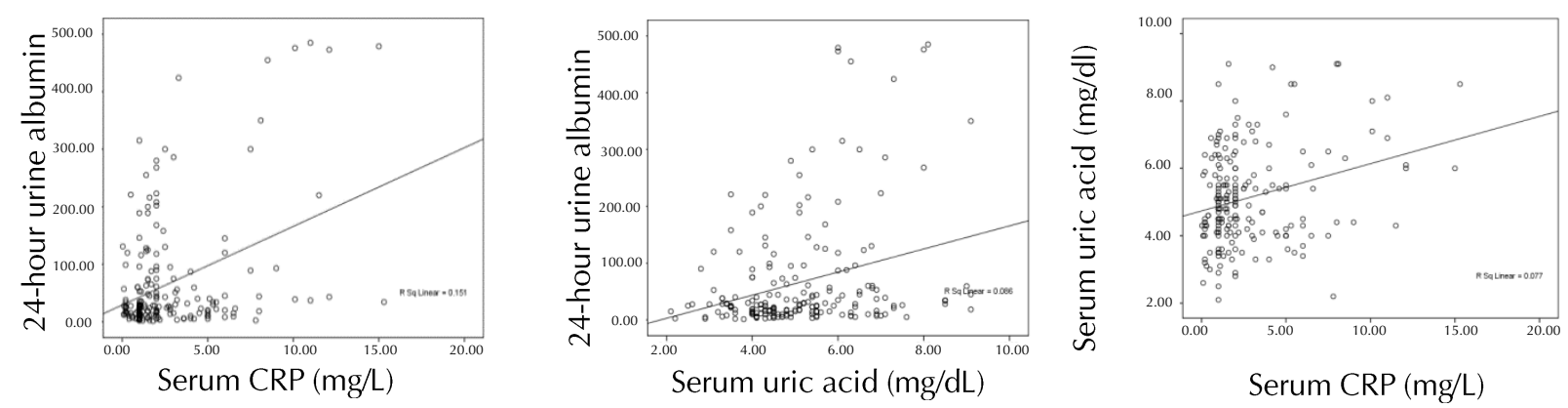

Figure 1. Linear diagram of separate correlation of serum CRP and serum uric acid with 24-hour urine albumin concentration (two leftside diagrams). The right dots plot shows the relationship between serum CRP and uric acid concentration.

$\mathrm{HbA}_{1} \mathrm{C}$. However, a study in 2011 showed a negative correlation between SUA and $\mathrm{HbA}_{1} \mathrm{C}$ or fasting blood sugar (20). Hyperuricemia has been also recently focused as a risk factor of cardiovascular diseases as well as metabolic syndrome (21). Furthermore, some count on hyperuricemia and metabolic syndrome as independent predictors of CKD in T2DM (22). In another study published in 2016 by Solbu et al, SUA was unexpectedly associated with albuminuria in a positive manner (23). Since approximately $70 \%$ of SUA is eliminated by kidney and reabsorbed up to $90 \%$ in kidney, it can be actually involved in chronic kidney disease (CKD) as Dousdampanis et al, pointed out in 2014 (24). Hyperuricemia is due to impaired renal excretion of uric acid in $90 \%$ of cases (25). Diabetes is one of the main causes of CKD and microvascular complications of DM are associated with hyperuricemia in terms of pathogenesis (26). Hyperuricemia (HUA) is, in turn, a predisposing factor for hypertension and consequently cardiovascular mortality as animal studies believe $(27,28)$. Diabetic nephropathy could be considered as one of the causal factors for end-stage renal disease as well. Likely, hyperuricemia can direct insulin resistance to develop hyperinsulinemia (29). On the contrary, Zhang et al, believed that HUA could disturb the glucose metabolism via an increased oxidative stress as well as inhibition of pancreatic $\beta$ cells (30). In obese diabetic cases, hyperuricemia is not unusual since obesity predispose T2DM in some individuals among whom an increased hepatic production of uric acid is expected. It suggests a link between obesity, diabetes and uric acid changes (31) and also CKD independently of other metabolic syndrome components, (32) although we found no relationship between BMI and SUA in the current study. The correlation between uric acid and albuminuria is a

Table 4. Correlation of several demographic and clinical parameters with the level of albuminuria in our participants

\begin{tabular}{|c|c|c|c|c|c|}
\hline & Albuminuria & $\mathbf{N}$ & Mean $\pm S D$ & Test value & $P$ value \\
\hline \multirow{3}{*}{ Age } & Macroalbuminuria & 8 & $54.94 \pm 9.12$ & \multirow{3}{*}{$t=0.69$} & \multirow{3}{*}{0.49} \\
\hline & Microalbuminuria & 79 & $54.76 \pm 8.11$ & & \\
\hline & Normal & 113 & $54.2 \pm 9.5$ & & \\
\hline \multirow{3}{*}{ BMI } & Macroalbuminuria & 8 & $26.61 \pm 3.46$ & \multirow{3}{*}{$\mathrm{T}=0.26$} & \multirow{3}{*}{0.78} \\
\hline & Microalbuminuria & 79 & $26.54 \pm 3.12$ & & \\
\hline & Normal & 113 & $26.52 \pm 3.45$ & & \\
\hline \multirow{3}{*}{ Duration of DM } & Macroalbuminuria & 8 & $8.11 \pm 5.12$ & \multirow{3}{*}{$Z=0.3$} & \multirow{3}{*}{0.76} \\
\hline & Microalbuminuria & 79 & $8.45 \pm 5.76$ & & \\
\hline & Normal & 113 & $8.23 \pm 5.98$ & & \\
\hline \multirow{3}{*}{ SBP (mm Hg) } & Macroalbuminuria & 8 & $126.79 \pm 16.64$ & \multirow{3}{*}{$Z=1.63$} & \multirow{3}{*}{0.102} \\
\hline & Microalbuminuria & 79 & $126.89 \pm 16.49$ & & \\
\hline & Normal & 113 & $123.89 \pm 16.95$ & & \\
\hline \multirow{3}{*}{ DBP (mm Hg) } & Macroalbuminuria & 8 & $77.14 \pm 8.13$ & \multirow{3}{*}{$Z=0.99$} & \multirow{3}{*}{0.321} \\
\hline & Microalbuminuria & 79 & $77.34 \pm 8.97$ & & \\
\hline & Normal & 113 & $76.19 \pm 8.13$ & & \\
\hline \multirow{3}{*}{ Male } & Macroalbuminuria & 5 & - & - & \multirow{6}{*}{0.15} \\
\hline & Microalbuminuria & 47 & - & - & \\
\hline & Normal & 56 & - & - & \\
\hline \multirow{3}{*}{ Female } & Macroalbuminuria & 3 & - & - & \\
\hline & Microalbuminuria & 32 & - & - & \\
\hline & Normal & 57 & - & - & \\
\hline \multirow{3}{*}{ Smoker } & Macroalbuminuria & 6 & - & - & \multirow{3}{*}{0.3} \\
\hline & Microalbuminuria & 64 & - & - & \\
\hline & Normal & 84 & - & - & \\
\hline
\end{tabular}



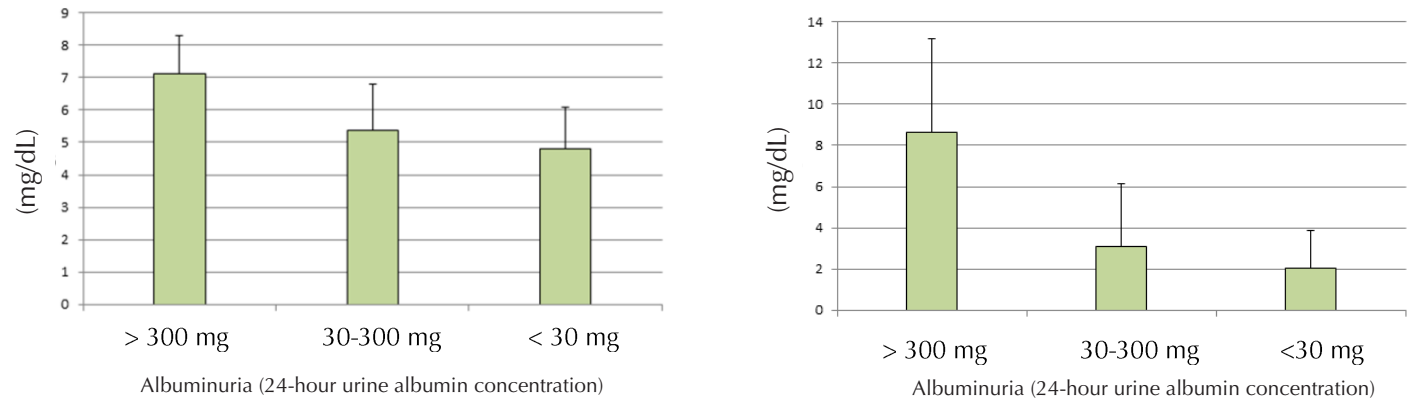

Figure 2. Distribution of albuminuria including micro and macro-albuminuria in patients with T2DM participating in the current study. The left chart belongs to the concentration of uric acid and the right one shows serum levels of CRP.

very important issue to rise in diabetic cases and evidence support the role of baseline SUA levels in the prediction of persistent macro-albuminuria in type1DM $(33,34)$. Ficociello et al computed that $1 \mathrm{mg} / \mathrm{dL}$ rise in SUA level could increase the risk of micro- or macro- albuminuria by $80 \%$ which could be led by GFR loss in type $1 \mathrm{DM}$ patients (35). BO et al showed a correlation between HUA and early onset of diabetic nephropathy in patients with T2DM $(36,37)$.

Several studies highlighted the effect of lowering SUA on the progression of diabetic nephropathy; one of whom was a research team led by Momeni et al, who administered allopurinol in 40 patients with T2DM in 2010 in Iran. They determined a decrease in proteinuria only in 4 months of treatment (38).

Uric acid has another interesting role which is mostly predominant in vascular smooth muscle cells where promotes inflammation when activates NF-K $\beta$ and enhances CRP expression (15). Studies show that CRP and uric acid may make an interact in the development of albuminuria and contribute to the progression towards CKD in patients with T2DM (39-41). Hence, it was not too strange to report increased CRP in serum along with HUA through the current study. In 2005, Kang et al focused on the primitive effect of uric acid on CRP expression via endothelial dysfunction and pathologic vascular remodeling (15). There is evidence of a systemic inflammatory response in individuals with hypertension or cardiovascular disease which is marked mainly by elevated serum CRP. CRP is a well-known marker for myocardial infarction, stroke and vascular death and CKD $(42,43)$. CRP is not only a marker, but also facilitates apoptosis in endothelial cells in addition to being an active factor in plaque formation and cardiovascular

Table 5. Correlation of some important laboratory parameters with the level of albuminuria with the test values and significance. Beside SUA and $\mathrm{CRP}$, serum triglyceride was the only factor to associate with the severity of albuminuria in our participants in term of general laboratory measures

\begin{tabular}{|c|c|c|c|c|c|}
\hline Lab parameters & Albuminuria & $\mathbf{n}$ & Mean $\pm S D$ & Test value & $P$ value \\
\hline \multirow{3}{*}{ FBS (mg/dL) } & Macroalbuminuria & 8 & $137.37 \pm 40.63$ & & \\
\hline & Microalbuminuria & 79 & $134.56 \pm 36.1$ & $Z=3.74$ & 0.154 \\
\hline & Normal & 113 & $143.69 \pm 39.8$ & & \\
\hline \multirow{3}{*}{$\mathrm{HBA}_{1} \mathrm{C}$} & Macroalbuminuria & 8 & $7.23 \pm 0.36$ & & \\
\hline & Microalbuminuria & 79 & $7.45 \pm 1.29$ & $Z=0.86$ & 0.649 \\
\hline & Normal & 113 & $7.39 \pm 1.54$ & & \\
\hline \multirow{3}{*}{ TG (mmol/L) } & Macroalbuminuria & 8 & $141.37 \pm 56.32$ & & \\
\hline & Microalbuminuria & 79 & $139.81 \pm 55.99$ & $Z=7.37$ & 0.025 \\
\hline & Normal & 113 & $163.73 \pm 66.3$ & & \\
\hline \multirow{3}{*}{ Chol(mmol/L) } & Macroalbuminuria & 8 & $170.62 \pm 48.62$ & & \\
\hline & Microalbuminuria & 79 & $162.91 \pm 46.84$ & $Z=2.97$ & 0.22 \\
\hline & Normal & 113 & $172.67 \pm 45.28$ & & \\
\hline \multirow{3}{*}{ LDL (mmol/L) } & Macroalbuminuria & 8 & $95.0 \pm 21.66$ & & \\
\hline & Microalbuminuria & 79 & $93.22 \pm 32.17$ & $Z=3.93$ & 0.14 \\
\hline & Normal & 113 & $102.32 \pm 37.12$ & & \\
\hline \multirow{3}{*}{$\mathrm{HDL}(\mathrm{mmol} / \mathrm{L})$} & Macroalbuminuria & 8 & $37.87 \pm 9.77$ & & \\
\hline & Microalbuminuria & 79 & $38.53 \pm 8.53$ & $Z=0.902$ & 0.63 \\
\hline & Normal & 113 & $41.0 \pm 11.84$ & & \\
\hline \multirow{3}{*}{ SUA (mg/dL) } & Macroalbuminuria & 8 & $7.11 \pm 1.18$ & & \\
\hline & Microalbuminuria & 79 & $5.37 \pm 1.42$ & $Z=20.5$ & $<0.001$ \\
\hline & Normal & 113 & $4.79 \pm 1.29$ & & \\
\hline \multirow{3}{*}{ CRP (mg/L) } & Macroalbuminuria & 8 & $8.63 \pm 4.58$ & & \\
\hline & Microalbuminuria & 79 & $3.08 \pm 3.04$ & $Z=20.47$ & $<0.001$ \\
\hline & Normal & 113 & $2.05 \pm 1.81$ & & \\
\hline
\end{tabular}


morbidity (44). Despite the antioxidant role which some authors consider for uric acid (45) many authors believe in high levels of uric acid as a promoter for systemic inflammation, CRP expression, endothelial dysfunction, hypertension and cardiovascular diseases (46). Kang et al investigated the role of uric acid in CRP synthesis to suggest a pathologic linkage between uric acid and CRP in diabetes and cardiovascular diseases as well as CKD (39). Finally, CRP is considered more than a biomarker of inflammation since evidence shows that CRP has also a direct effect to promote atherosclerotic process and endothelial cell dysfunction (15).

However, albuminuria and its correlation with two main parameters including SUA and CRP were important factors to assess in the current study. We found a strong linear correlation in this regard although there were not big ORs to discuss.

There was no correlation between albuminuria and lipid profile, FBS, $\mathrm{HbA}_{1} \mathrm{C}$, blood pressure and medications throughout our study.

\section{Conclusion}

It seems that uric acid and CRP levels in serum are the most reliable parameters studied by the current study to predict life-threatening diabetic consequences like cardiovascular disease (CVD) and CKD in patients with T2DM

\section{Limitations of the study}

This study conducted with a small sample size and the results should be validated by multi-centric studies with larger sample size.

\section{Authors' contribution}

FS; study design, preparation of the manuscript, and final revision. HR; study design, data gathering, manuscript preparation.

\section{Conflicts of interest}

The authors declared no competing interests.

\section{Ethical Considerations}

Ethical issues (including plagiarism, data fabrication, double publication) have been completely observed by the authors.

\section{Funding/Support}

None.

\section{References}

1. Ritz E, Rychlik I, Locatelli F, Halimi S: End-stage renal failure in type 2 diabetes: A medical catastrophe of worldwide dimensions. Am J Kidney Dis. 1999;34:795-808, 1999. doi: 10.1016/S0272-6386(99)70035-1.

2. Gross JL, de Azevedo MJ, Silveiro SP, Canani LH, Caramori ML, Zelmanovitz T. Diabetic nephropathy: diagnosis, prevention, and treatment. Diabetes Care 2005;28:164-76.

3. De Cosmo S, Viazzi F, Pacilli A, Giorda C, Ceriello A, Gentile S, et al. Serum Uric Acid and Risk of CKD in Type
2 Diabetes. Clin J Am Soc Nephrol. 2015;10:1921-9. doi: 10.2215/CJN.03140315.

4. Orasanu G, Plutzky J. The pathologic continuum of diabetic vascular disease. J Am Coll Cardiol 2009;53:S35-42. doi: 10.1016/j.jacc.2008.09.055.

5. Festa A, D’Agostino R, Howard G, Mykkanen L,Tracy RP, Haffner SM. Chronic subclinical inflammation as part of the insulin resistance syndrome. Circulation 2000;102:42-7. doi: 10.1161/01.CIR.102.1.42.

6. Sesso HD, Buring JE, Rifai N, Blake GJ, Gaziano JM, Ridker PM. C-reactive protein and the risk of developing hypertension. JAMA. 2003;290:2945-51. doi: 10.1001/ jama.290.22.2945.

7. Sahakyan K, Klein BE, Lee KE, Tsai MY, Klein R. Inflammatory and endothelial dysfunction markers and proteinuria in persons with type 1 diabetes mellitus. Eur J Endocrinol 2010;162:1101-5. doi: 10.1530/EJE-10-0049.

8. Johnson RJ, Kang DH, Feig D, Kivlighn S, Kanellis J, Watanabe $\mathrm{S}$, et al. Is there a pathogenetic role for uric acid in hypertension and cardiovascular and renal disease? Hypertension. 2003;41:1183-90. doi: 10.1161/01. HYP.0000069700.62727.C5.

9. Behradmanesh S, Karami Horestani M. Association of serum uric acid with proteinuria in type 2 diabetic patients. Caspian J Intern Med. 2014;5:17-21.

10. Alper AB Jr, Chen W, Yau L, Srinivasan SR, Berenson GS, Hamm LL. Childhood uric acid predicts adult blood pressure: the Bogalusa Heart Study. Hypertension. 2005;45:34-8. doi: 10.1161/01.HYP.0000150783.79172.bb.

11. Soltani Z, Rasheed K, Kapusta DR, Reisin E. Potential role of uric acid in metabolic syndrome, hypertension, kidney injury, and cardiovascular diseases: is it time for reappraisal? Curr Hypertens Rep. 2013;15:175-81. doi: 10.1007/s11906013-0344-5.

12. Viazzi F, Leoncini G, Vercelli M, Deferrari G, Pontremoli R. Serum uric acid levels predict new-onset type 2 diabetes in hospitalized patients with primary hypertension: the MAGIC study. Diabetes Care. 2011;34:126-8. doi: 10.2337/dc10-0918.

13. Bhole V, Choi JW, Kim SW, de Vera M, Choi H. Serum uric acid levels and the risk of type 2 diabetes: a prospective study. Am J Med. 2010;123:957-61. doi: 10.1016/j. amjmed.2010.03.027.

14. Cai XL, Han XY, Ji LN. High-normal serum uric acid is associated with albuminuria and impaired glomerular filtration rate in Chinese type 2 diabetic patients. Chin Med J. 2011;124:3629-34.

15. Kang DH, Park SK, Lee IK, Johnson RJ. Uric acidinduced C-reactive protein expression: implication on cell proliferation and nitric oxide production of human vascular cells. J Am Soc Nephrol. 2005;16:3553-62. doi: 10.1681/ ASN.2005050572.

16. Bonakdara S, Maryam H. Hyperuricemia and albuminuria in patients with type 2 diabetes mellitus. Iran J Kidney Dis. 2011;5:21-4.

17. Ling Y, Li XM, Gao X. Cross-sectional association of serum $\mathrm{C}$-reactive protein and uric acid with albuminuria in Chinese type 2 diabetic patients. Chin Med J (Engl) 2013; 126: 4023-9.

18. Navarro JF, Mora C, Maca M, Garca J. Inflammatory parameters are independently associated with urinary albumin in type 2 diabetes mellitus. Am J Kidney Dis. 2003;42:53-61.

19. Fraser SD, Roderick PJ, McIntyre NJ, Harris S, McIntyre C, Fluck R, Taal MW. Assessment of proteinuria in patients with chronic kidney disease stage 3: albuminuria and non- 
albumin proteinuria. PLOS One. 2014;27;9:e98261. doi: 10.1371/journal.pone.0098261.

20. Li Q, Yang Z, Lu B, Wen J, Ye Z, Chen L, et al. Serum uric acid level and its association with metabolic syndrome and carotid atherosclerosis in patients with type 2 diabetes. Cardiovascular Diabetology 2011;10:72-8. doi: 10.1186/1475-2840-10-72.

21. Mankovsky B, Kurashvili R, Sadikot S.Is serum uric acid a risk factor for atherosclerotic cardiovascular disease? A review of the clinical evidence. Part 1. Diabetes and Metabolic Syndrome: Clinical Research and Reviews. 2010; 4:176-184. doi: 10.1016/j.dsx.2010.07.010.

22. Viazzi F, Piscitelli P, Giorda C, Ceriello A, Genovese S, Russo $\mathrm{G}$, et al. Metabolic syndrome, serum uric acid and renal risk in patients with T2D. PLoS One. 2017;12:e0176058. doi: 10.1371/journal.pone.0176058.

23. Solbu MD, Norvik JV, Storhaug HM, Eriksen BO, Melsom $\mathrm{T}$, Eggen $\mathrm{AE}$, et al. The association between adiponectin, serum uric acid and urinary markers of renal damage in the general population: cross-sectional data from the Tromsø Study. Kidney Blood Press Res. 2016;41:623-634. doi: $10.1159 / 000447931$.

24. Dousdampanis P, Trigka K, Musso CG, Fourtounas C. Hyperuricemia and chronic kidney disease: an enigma yet to be solved. Ren Fail. 2014;36:1351-9. doi: $10.3109 / 0886022 X .2014 .947516$.

25. Edwards NL. The role of hyperuricemia and gout in kidney and cardiovascular disease. Cleve Clin J Med. 2008;75:S13-6.

26. Sinha SK, Shaheen M, Rajavashisth TB, Pan D, Norris KC, Nicholas SB. Association of race/ethnicity, inflammation, and albuminuria in patients with diabetes and early chronic kidney disease. Diabetes Care. 2014;37:1060-8. doi: 10.2337/ dc13-0013.

27. Mazzali M, Kanellis J, Han L, Feng L, Xia YY, Chen Q, et al. Hyperuricemia induces a primary renal arteriolopathy in rats by a blood pressure-independent mechanism. Am J Physiol Renal Physiol. 2002;282:F991-7. doi: 10.1152/ ajprenal.00283.2001.

28. Watanabe S, Kang DH, Feng L, Nakagawa T, Kanellis J, Lan $\mathrm{H}$, et al. Uric acid, hominoid evolution, and the pathogenesis of salt-sensitivity. Hypertension 2002;40:355-60.

29. Sowers JR. Diabetes mellitus and vascular disease. Hypertension 2013; 61: 943-7.

30. Tsuda K. Oxidative Stress Participates in the Associations Between Serum Uric Acid and Albuminuria in the Obesity. Am J Hypertens. 2017;30:e1. doi: 10.1093/ajh/hpw162.

31. Khitan Z, Kim DH. Fructose: A key factor in the development of metabolic syndrome and hypertension. J Nutr Metab. 2013;2013:682673. doi: 10.1155/2013/682673.

32. Jiang L, Huang W, Liang Y, Wang F, Duan X, Yang $\mathrm{X}$, et al. Metabolic syndrome, C-reactive protein and microalbuminuria in a rural Chinese population: a cross-sectional study. BMC Nephrol. 2013;14:118. doi: 10.1186/1471-2369-14-118.

33. Radcliffe NJ, Seah JM, Clarke M, MacIsaac RJ, Jerums G, Ekinci EI. Clinical predictive factors in diabetic kidney disease progression. J Diabetes Investig. 2017;8:6-18. doi: 10.1111/jdi.12533.

34. Hayashino Y, Okamura S, Tsujii S, Ishii H. Association of serum uric acid levels with the risk of development or progression of albuminuria among Japanese patients with type 2 diabetes: a prospective cohort study [Diabetes Distress and Care Registry at Tenri (DDCRT 10)]. Acta Diabetol. 2016;53:599-607. doi: 10.1007/s00592-015-0825-x.

35. Ficociello LH, Rosolowsky ET, Niewczas MA, et al. Highnormal serum uric acid increases risk of early progressive renal function loss in type 1 diabetes: results of a 6-year follow-up. Diabetes Care. 2010;33:1337-43. doi: 10.2337/ dc10-0227.

36. Bartáková V, Kuricová $\mathrm{K}$, Pácal L, Nová Z, Dvořáková V, Švrčková M, et al. Hyperuricemia contributes to the faster progression of diabetic kidney disease in type 2 diabetes mellitus. J Diabetes Complications 2016;30:1300-7. doi: 10.1016/j.jdiacomp.2016.06.002.

37. Takae K, Nagata M, Hata J, Mukai N, Hirakawa Y, Yoshida $\mathrm{D}$, et al. Serum uric acid as a risk factor for chronic kidney disease in a japanese community- The Hisayama Study. Circ J. 2016;80:1857-62. doi: 10.1253/circj.CJ-16-0030.

38. Momeni A, Shahidi S, Seirafian S, Taheri S, Kheiri S. Effect of allopurinol in decreasing proteinuria in type 2 diabetic patients. Iran J Kidney Dis. 2010;4:128-32.

39. Ling Y, Li XM, Gao X. Cross-sectional association of serum C-reactive protein and uric acid with albuminuria in Chinese type 2 diabetic patients. Chin Med J (Engl). 2013;126:4023-9.

40. Hayashino Y, Mashitani T, Tsujii S, Ishii H. Serum highsensitivity C-reactive protein levels are associated with high risk of development, not progression, of diabetic nephropathy among Japanese type 2 diabetic patients: a prospective cohort study (Diabetes Distress and Care Registry at Tenri [DDCRT7]). Diabetes Care. 2014;37: 2947-52. doi: 10.2337/ dc14-1357.

41. Guessous I, Ponte B, Marques-Vidal P, Paccaud F, Gaspoz JM, Burnier M, et al. Clinical and biological determinants of kidney outcomes in a population-based cohort study. Kidney Blood Press Res. 2014;39:74-85. doi: 10.1159/000355779.

42. Ridker PM, Rifai N, Rose L, Buring JE, Cook NR: Comparison of C-reactive protein and low-density lipoprotein cholesterol levels in the prediction of first cardiovascular events. N Engl J Med. 2002;347:1557-65. doi: 10.1056/NEJMoa021993.

43. Arnold LW, Hoy WE, Wang Z. High C-reactive protein levels increase risk for chronic kidney disease hospitalisations in adults of a remote Indigenous Australian community - A prospective cohort study. Nephrology. 2017;22:699-705. doi:10.1111/nep.12841.

44. Verma S, Kuliszewski MA, Li SH, et al. C-reactive protein attenuates endothelial progenitor cell survival, differentiation, and function: Further evidence of a mechanistic link between C-reactive protein and cardiovascular disease. Circulation 2004;109:2058-67. doi: 10.1161/01.CIR.0000127577.63323.24.

45. Johnson RJ, Kang DH, Feig D, Kivlighn S, Kanellis J, Watanabe $S$, et al. Is there a pathogenetic role for uric acid in hypertension and cardiovascular and renal disease? Hypertension 2003;41:1183-90.

46. Moura Rdo S, Vasconcelos DF, Freitas E, Moura FJ, Rosa TT, Veiga JP. Cystatin C, CRP, log TG/HDLc and metabolic syndrome are associated with microalbuminuria in hypertension. Arq Bras Cardiol. 2014;102:54-9.

Copyright $\odot 2018$ The Author(s); Published by Nickan Research Institute. This is an open-access article distributed under the terms of the Creative Commons Attribution License (http://creativecommons.org/licenses/by/4.0), which permits unrestricted use, distribution, and reproduction in any medium, provided the original work is properly cited. 